\title{
REGIME DE LUZ EM UMA FLORESTA ESTACIONAL SEMIDECÍDUA SOB MANEJO, EM PIRENÓPOLIS, GOIÁS ${ }^{1}$
}

\begin{abstract}
Fábio Venturoli ${ }^{2}$, Augusto César Franco ${ }^{3}$, Christopher William Fagg ${ }^{4}$ e Jeanine Maria Felfili ${ }^{4}$
RESUMO - Esta pesquisa foi realizada em um fragmento de floresta estacional semidecídua, localizada em Pirenópolis, Goiás, e investigou as alterações no regime de luz, medida pela densidade de fluxo de fótons, associadas a intervenções silviculturais que visaram, sobretudo, aumentar o crescimento de espécies arbóreas, sem permitir a invasão por espécies oportunistas que poderiam influenciar negativamente a dinâmica da regeneração natural. O delineamento foi em blocos casualizados, em esquema fatorial, testando as diferenças entre tratamentos silviculturais, estações climáticas e alturas de medida no sub-bosque (1,30 m e ao nível do solo). Foram testadas duas intensidades de corte seletivo de indivíduos arbóreos e de cipós na floresta. Os tratamentos foram suficientes para alterar o regime de luz, tanto na estação seca como na estação chuvosa, em acordo com a hipótese testada. O sombreamento na área controle foi de $97 \%$ na estação chuvosa e de $86 \%$ na estação seca, apresentando diferenças significativas com o sombreamento associado aos tratamentos silviculturais, que variaram de $93 \%$ a $94 \%$ na chuva e de $77 \%$ a $80 \%$ na seca. Esse estudo pode auxiliar na validação deste sistema de manejo florestal proposto para as florestas estacionais semidecíduas no Brasil Central, devendo ser associado aos estudos populacionais e de comunidade, preservando os fragmentos florestais encontrados na região e gerando benefícios ambientais e renda extra para a população rural.
\end{abstract}

Palavras-chave: Intervenções silviculturais, Densidade de fluxo de fótons e Abertura do dossel.

\section{LIGHT AVAILABILITY IN A SEMIDECIDUOUS FOREST MANAGEMENT IN PIRENÓPOLIS, GOIÁS, BRAZIL}

\begin{abstract}
This study was carried out on a fragment of semi-deciduous forest in Pirenópolis, Goias, Brazil and investigated the changes in the photon flux density in relation to silvicultural interventions that aimed at increasing growth of tree species but without allowing invasion by exotic species that could influence the dynamics of natural regeneration. The design was a randomized block in factorial, testing the differences between silvicultural treatments, seasons and heights in the understory (1.30 $\mathrm{m}$ versus at the ground level). We tested two intensities of selective cutting of individual trees and vines in the forest. The treatments were sufficient to alter the understory light, both in the dry season and rainy season, in agreement with the hypothesis tested. The shading in the control area was $97 \%$ in the rainy season and $86 \%$ in the dry season, showing significant differences with the shading associated with silvicultural treatments, which ranged from $93 \%$ to $94 \%$ in the rainy season and from $77 \%$ to $80 \%$ in the dry season. This study may assist this forest management system for semi-deciduous forests in Central Brazil, and should be linked to population studies and community, preserving the forest fragments found in the region and generating numerous environmental benefits and extra income for the rural population.
\end{abstract}

Keywords: Canopy gaps, Photon flux density and Silvicultural treatments.

\footnotetext{
${ }^{1}$ Recebido em 09.01.2012 aceito para publicação em 04.06.2012

${ }^{2}$ Universidade Federal de Goiás, Escola de Agronomia e Engenharia de Alimentos, curso de Engenharia Florestal, Goiânia, Goiás. E-mail:<fabioventuroli@ agro.ufg.br>.

${ }^{3}$ Universidade de Brasília, Instituto de Ciências Biológicas, Departamento de Botânica. E-mail: <acfranco@ unb.br>.

${ }^{4}$ Universidade de Brasília, Faculdade de Tecnologia, Departamento de Engenharia Florestal. E-mail: <acaciafagg@ gmail.com>.
} 


\section{INTRODUÇÃO}

A disponibilidade de luz é um dos principais fatores que limitam o crescimento das plantas (DENSLOW et al., 1990; ZIPPERLEN; PRESS, 1996). Além disso, influencia a mortalidade e distribuição das espécies ao longo da sucessão florestal, sendo essencial para a fotossíntese (SWAINE; WHITMORE, 1988; KEELING; PHILLIPS, 2007).

É possível ainda identificar plasticidade de espécies em relação à densidade de fluxo de fótons (SOUSASILVA et al., 1999). Inclusive, pode-se classificá-las em grupos funcionais em razão de suas exigências por luz, como discutido por Swaine e Whitmore (1988) e por Whitmore (1989). No entanto, deve-se considerar que a amplitude de exigência de luz representa um contínuo de tolerância (AUGSPURGER, 1984; SOUZA; VÁLIO, 2001).

De maneira geral, a germinação e primeiro estágio de sucessão em florestas são favorecidos pela sombra (COLLET; CHENOST, 2006), mas entre os estágios mais avançados da regeneração a competição por luz é intensificada e a sombra pode impedir o desenvolvimento das plantas (WADSWORTH; ZWEEDE, 2006). Em florestas estacionais, como as árvores perdem as folhas na estação seca, aumenta muita a incidência de radiação solar no piso da floresta, o que pode provocar a dessecação e morte de plântulas, principalmente (VIEIRA; SCARIOT, 2006). Com isso, nessas florestas as espécies apresentam grande plasticidade nas exigências de luz.

Devido à forte influência da luz sobre o crescimento das árvores e da regeneração natural (SILVA et al., 1995; GERHARDT, 1996; PARIONA et al., 2003; CARVALHO et al., 2004; VENTUROLI et al., 2011a-c), assim como na colonização por espécies invasoras (D'ANTONIO; VITOUSEK, 1992; SCOLOWSKI; TAKAKI, 2007), o manejo em florestas secundárias deve buscar a abertura do dossel suficiente para obter o crescimento e regeneração de árvores desejáveis sem permitir a entrada de espécies indesejáveis e, ou, invasoras que possam interferir negativamente na regeneração natural (FREITAS, 2004).

Há ainda grande variação na Densidade de Fluxo de Fótons (DFF) que incide no sub-bosque das florestas. A DFF varia entre formações florestais; dentro destas, em razão da posição das folhas nas árvores (ROSSATTO et al., 2010); e entre gradientes climáticos, além de existir variação espacial (horizontal e vertical) e sobre escalas de tempo (de segundos a anos) dentro das florestas (JENNINGS et al., 1999; ENGELBRECHT; HERTZ, 2001; KEELING; PHILLIPS, 2007; WANG et al., 2007).

Em geral, menos do que 5\% da densidade de fluxo de fótons incidente no dossel alcança o solo das florestas tropicais úmidas (ZIPPERLEN; PRESS, 1996; KEELING; PHILLIPS, 2007), mas é suficiente para influenciar todo o desenvolvimento das plantas e os processos de sucessão (SWAINE e WHITMORE, 1988). Em florestas de galeria, a porcentagem de luz que atingiu o solo, sob o dossel, variou de $0,3 \%$ a $11 \%$; nas bordas, variou de $0,9 \%$ a $30 \%$; e em clareiras, a luminosidade que atingiu o solo variou de 4\% a 27\% (FELFILI; ABREU, 1999). Em floresta monodominante, Marimon (2005) encontrou porcentagens de sombreamento variando de $96,5 \%$ a $98,1 \%$ no sub-bosque.

Em florestas estacionais tropicais há grande diferença na DFF incidente no sub-bosque entre as estações seca e chuvosa, em razão da deciduidade das árvores do dossel na estação seca, podendo as florestas semidecíduas apresentar cobertura foliar arbórea de até $50 \%$ na estação seca, contra de $70 \%$ a $95 \%$ na estação chuvosa. Enquanto nas florestas deciduais o sombreamento pode ser de até $70 \%$ na estação chuvosa, contra percentuais inferiores a $50 \%$ na estação seca, como discutido por Veloso et al. (1991) e Pereira et al. (2011) e posteriormente corroborado por Ribeiro e Walter (1998), Felfili (2001) e Nascimento (2005). Este último, estudando variações espaciais e temporais da radiação solar em florestas estacionais decíduas no Vale do Rio Paranã, em Goiás, encontrou porcentagens de sombreamento variando de $25 \%$ a $32 \%$ na estação seca, contra de $90,4 \%$ a $94,3 \%$ na estação chuvosa.

Um dos principais objetivos do manejo florestal em florestas nativas é otimizar a disponibilidade de luz para a regeneração natural e para espécies comerciais remanescentes na floresta, visando aumentar o ritmo de crescimento das árvores, em razão da maior disponibilidade de luz, e com isso obter ciclos de corte mais curtos (SMITH, 1986; PAQUETTE et al., 2007). Assim, neste trabalho quantificou-se a DFF incidente no sub-bosque de uma Floresta Estacional Semidecidual Secundária, sob manejo, partindo-se da hipótese de que intervenções silviculturais aumentariam a disponibilidade de luz no sub-bosque, independentemente da estação climática, favorecendo

Revista Árvore, Viçosa-MG, v.36, n.6, p.1135-1144, 2012 
um sistema de manejo florestal proposto para as Florestas Estacionais Semideciduais do Brasil Central (VENTUROLI, 2008; VENTUROLI et al., 2011a).

O objetivo foi quantificar a entrada de luz em uma Floresta Estacional Semidecidual Secundária, sob manejo ao longo do dia, em duas estações climáticas (seca e chuva), entre duas alturas de medida $(1,30 \mathrm{~m}$ e ao nível do solo) e ao longo de três tratamentos silviculturais e de um controle.

As seguintes hipóteses foram testadas:

- A porcentagem de sombreamento na floresta é a mesma em todos os tratamentos silviculturais?

- A porcentagem de sombreamento na floresta é a mesma nas duas estações climáticas (seca e chuvosa)?

- A porcentagem de sombreamento na floresta é a mesma em duas alturas de medida (1,3m e ao nível do solo)?

- As diferenças nas porcentagens de sombreamento na floresta entre os tratamentos silviculturais são as mesmas nas duas estações climáticas?

- As diferenças nas porcentagens de sombreamento na floresta entre os tratamentos silviculturais são as mesmas nas duas alturas de medida?

- As diferenças nas porcentagens de sombreamento na floresta entre as duas alturas de medida são as mesmas nas duas estações climáticas?

- As diferenças nas porcentagens de sombreamento entre os tratamentos (ou alturas de medida, ou estações climáticas) são independentes dos outros dois fatores (testando a tripla interação)?

\section{MATERIAL E MÉTODOS}

A floresta em estudo localiza-se na Fazenda Vagafogo, no Município de Pirenópolis, Goiás (1549'S, $\left.48^{\circ} 59^{\prime} \mathrm{W}\right)$, e está a uma altitude média de $770 \mathrm{~m}$ acima do nível do mar. É caracterizada como fragmento de Floresta Estacional Semidecidual (IBGE, 2004).

Segundo a classificação de Köppen, o clima na região enquadra-se no tipo Aw, característico dos climas úmidos tropicais (A), com duas estações bem definidas: seca no inverno e úmida no verão (w) (NIMER, 1989). A temperatura média anual no Município de Pirenópolis é de $22^{\circ} \mathrm{C}$, variando de $16^{\circ} \mathrm{C}$ a $34^{\circ} \mathrm{C}$, e a precipitação média anual foi de $1.800 \mathrm{~mm}$, com um período de estiagem que ocorre anualmente de maio a agosto (INMET, 2006).
O ambiente onde foi montado o experimento é compreendido por uma Floresta Estacional de Encosta, que está sob a influência de um gradiente ambiental de umidade, definido pela proximidade de um córrego em um extremo e um Cerrado stricto sensu, nas partes mais altas do relevo, no outro extremo. Os solos predominantes são classificados como Neossolo Litólicos (IBGE, 2001), podendo ser considerados como Entisols (BRADY; WEIL, 2001).

Em abril de 2003 foram instaladas 16 parcelas de $25 \times 30 \mathrm{~m}$, adjacentes umas às outras e respeitandose uma distância de $60 \mathrm{~m}$ da floresta de galeria, em direção a relevos mais altos sob a influência de Cerrado stricto sensu. No canto superior das parcelas de 25 x $30 \mathrm{~m}$, em uma faixa de 5 x $30 \mathrm{~m}$, foram identificados todos os indivíduos que apresentavam circunferências à altura do peito (cerca de 1,3 $\mathrm{m}$ de altura) superiores a $9 \mathrm{~cm}(\mathrm{CAP}>9 \mathrm{~cm})$. Essa amostragem permitiu realizar uma análise de ordenação por Detrended Correspondence Analysis - DCA (KENT, 2012), com o objetivo de espacializar a composição florística em relação ao gradiente ambiental de umidade, conforme recomendado por Kent e Coker (1992), e, assim, prescrever o delineamento experimental.

Os resultados da ordenação por DCA permitiram propor o delineamento experimental em blocos casualizados. A DCA posicionou juntas as parcelas com maiores similaridades florísticas, o que coincidiu com a distância das parcelas ao córrego, indicando hábitats diferentes.

A definição das parcelas que compuseram cada bloco seguiu o gradiente de umidade compreendido entre a borda da floresta de galeria, a maior umidade e a proximidade com o Cerrado stricto sensu, claramente identificado na ordenação (FELFILI et al., 2005; VENTUROLI, 2008). A distribuição dos blocos na floresta ficou assim determinada:

- BLOCO I-ambiente de maior influência ripária (distante \pm 60 metros do córrego).

- BLOCO II - ambiente sob menor influência ripária do que o bloco I (distante do córrego 90 metros).

- BLOCO III - menor influência ripária, maior distância do córrego e mais próximo ao cerrado stricto sensu.

- BLOCO IV - transição floresta-cerrado, ambiente mais seco.

Revista Árvore, Viçosa-MG, v.36, n.6, p.1135-1144, 2012 
Após o inventário da comunidade e a definição do delineamento experimental, o procedimento adotado foi classificar as espécies em toda a parcela $(25$ x 30 m), identificando e medindo as árvores consideradas desejáveis e, então, proceder à aplicação dos tratamentos silviculturais de estímulo ao crescimento.

Foram classificadas como desejáveis as árvores que possuíam circunferência à altura do peito (CAP) maior do que $9 \mathrm{~cm}$ e apresentavam boas características silviculturais, como fuste retilíneo, copa bem formada e poucos galhos, que estavam aparentemente sadias, sem problemas fitossanitários; e as que possuíam reconhecido valor econômico, como aquelas produtoras de madeira, frutos, resinas e outros produtos utilizáveis pelo homem.

As árvores desejáveis foram numeradas sequencialmente, com placas de alumínio, totalizando 2.670 árvores em 1,2 ha.

\subsection{Tratamentos Silviculturais}

Após conhecida a composição florística e definidos os blocos, cada uma das quatro parcelas experimentais que compunham cada bloco foi aleatoriamente submetida a um dos seguintes tratamentos:

- T1 - controle;

- T2 - liberação de 1 metro de raio para as árvores desejáveis. Eliminou-se a competição (árvores com CAP $>9 \mathrm{~cm}$ ) dentro de um raio de $1 \mathrm{~m}$ em relação a cada árvore desejável;

- T3 - idem T2 mais corte de cipós em toda a área da parcela; e

- T4 - idem T3 mais plantio de enriquecimento com cinco mudas de Dipteryx alata Vogel e cinco mudas de Myracrodruon urundeuva Alemão, espaçadas em 4 metros.

A escolha das espécies para o enriquecimento foi baseada em sua importância econômica. D. alata é muito explorada na região e tem valor tanto madeireiro quanto alimentício. M. urundeuva é uma espécie muito explorada no Brasil e possui alto valor madeireiro, sendo comumente utilizada como mourões de cerca e postes. O número de indivíduos foi estabelecido em razão do tamanho das parcelas, que são consideradas pequenas e por já possuírem alta densidade de árvores.
A cada seis meses, as rebrotas de árvores e de cipós cortados eram novamente removidas nas parcelas, para manutenção do experimento.

\subsection{Densidade de Fluxo de Fótons}

A densidade de fluxo de fótons - DFF ( $\mu$ mol.m-2 ${ }^{2}$ s- $^{-1}$ ) foi estimada com a utilização de sensores de quanta, na faixa fotossinteticamente ativa. Os sensores foram previamente calibrados, um contra o outro, sob a condição uniforme de pleno sol.

Nas avaliações, um sensor ficou localizado no interior da floresta (sensor de quanta LI-190 S, Li-cor Inc., USA) e o outro a pleno sol (sensor de quanta ELE, SkyeInstruments, UK). Para cada medida tomada no interior da floresta, outra medida era tomada, simultaneamente, ao lado de fora da floresta, a pleno sol. Essa técnica permitiu, por comparação, quantificar a quantidade de luz que conseguia atravessar o dossel da floresta até a altura dos sensores.

As avaliações ocorreram durante quatro dias consecutivos, um dia para cada bloco do delineamento experimental, e foram realizadas em duas ocasiões diferentes, uma ao final da estação chuvosa (de 07 a 10 de junho de 2006) e outra no auge da estação seca (de 29 de agosto a $1^{\circ}$ de setembro de 2007). As medidas foram tomadas das 7 h30 às $17 \mathrm{~h} 20$.

Dentro da floresta, em cada parcela experimental as medidas foram tomadas em duas alturas diferentes, ao nível do solo e a 1,3 m de altura. As medições ocorreram nos cantos de uma área quadrangular de $4 \mathrm{~m}^{2}(2 \times 2$ $\mathrm{m})$, localizada no centro de cada parcela experimental ( $25 \times 30 \mathrm{~m})$, e foram tomadas em intervalos regulares de $30 \mathrm{seg}$ dentro de cada parcela e de 10 min entre as parcelas.

Em todas as avaliações, procurou-se manter o sensor nivelado horizontalmente com o auxílio de plataformas e estacas de madeira que foram previamente fixadas no local, para facilitar a operação, conforme metodologia descrita por Felfili e Abreu (1999).

Na estação seca, os dias avaliados eram ensolarados e sem nuvens e, na estação chuvosa, apesar de ensolarado, muitas nuvens cobriam o céu em determinados períodos ao longo do dia.

Os valores médios da DFF foram obtidos pela integração da curva diária de luz incidente no subbosque da floresta e a pleno sol, nas duas estações climáticas, entre os tratamentos e alturas de medida. 
A porcentagem de sombreamento no sub-bosque da floresta estudada foi calculada pela razão entre os valores médios da densidade de fluxo de fótons ao longo do dia, no interior da floresta e a pleno sol, conforme a seguinte equação:

$$
\mathrm{S}(\%)=\left[1-\left(\frac{\mathrm{DEF}_{\text {mata }}}{\mathrm{DEF}_{\text {sol }}}\right)\right] \times 100
$$

$\mathrm{S}(\%)$ é o percentual de sombreamento estimado

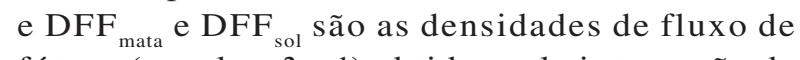
fótons ( $\mu$ mol.m- $\left.\mathbf{m}^{2} \cdot \mathrm{s}^{-1}\right)$ obtidas pela integração da curva diária de luz, na floresta e a pleno sol, respectivamente.

Os percentuais de sombreamento foram transformados para atingir distribuição normal, conforme a Equação 2 e posteriormente foram testados por Análise de Variância -ANOVA, a 5\% de probabilidade (ZAR, 2010).

$$
\mathrm{S}(\%)=\operatorname{seno}^{-1} \sqrt{\mathrm{S}(\%)}
$$

A Análise de Variância das porcentagens de sombreamento na floresta considerou o delineamento em blocos casualizados em esquema fatorial, com três fatores: os tratamentos silviculturais, em quatro níveis; as alturas de medida, em dois níveis; e as estações climáticas, em dois níveis. As combinações dos fatores obedeceram a uma classificação cruzada, com quatro repetições (blocos).

Os resultados foram apresentados de acordo com o seguinte modelo estatístico:

$$
\begin{aligned}
& Y_{i j k m}=\mu+\left(\frac{\left(\frac{B}{L}\right)}{A}\right)_{j k m}+T_{i}+A_{j}+L_{k}+T A_{i j}+T L_{i k}+ \\
& +A L_{j k}+T A L_{i j k}+\varepsilon_{i j k m}
\end{aligned}
$$

em que,

$\mu$ : média geral;

$\mathrm{T}_{\mathrm{i}}, \mathrm{A}_{\mathrm{j}}$ e $\mathrm{L}_{\mathrm{k}}$ : efeito de tratamentos, estações climáticas e alturas de medida, respectivamente;

$\mathrm{TA}_{\mathrm{ij}}, \mathrm{TL}_{\mathrm{ik}}$ e LA $\mathrm{Lik}_{\mathrm{j}}$ : efeito das interações de primeira ordem entre tratamentos e estações climáticas, tratamentos e alturas de medida e alturas de medida e estações climáticas, respectivamente
$\mathrm{TAL}_{\mathrm{ijk}}$ : efeito da interação tripla entre tratamentos, estações climáticas e alturas de medida;

$(\mathrm{B} / \mathrm{A}) / \mathrm{L}_{\mathrm{j} k \mathrm{~m}}$ : efeito de blocos dentro de estações climáticas, ambos dentro de alturas de medida; e

$\varepsilon_{\mathrm{ijkm}}$ : erro aleatório.

No caso de diferenças significativas na ANOVA entre tratamentos, alturas de medida ou estações climáticas, realizou-se o teste de Tukey a $5 \%$ de probabilidade, identificando-as.

\section{RESULTADOS}

A pleno sol, a densidade de fluxo de fótons - DFF variou de $90 \mu \mathrm{mol} \cdot \mathrm{m}^{-2} \cdot \mathrm{s}^{-1} \mathrm{a} 1.751 \mu \mathrm{mol} \cdot \mathrm{m}^{-2} \cdot \mathrm{s}^{-1}$, na estação seca, contra uma amplitude de variação que foi $90 \mu \mathrm{mol} . \mathrm{m}^{-2} \cdot \mathrm{s}^{-1}$ a $1.972 \mu \mathrm{mol} . \mathrm{m}^{-2} . \mathrm{s}^{-1}$ na estação chuvosa. No entanto, a DFF esteve predominantemente entre $739 \mu \mathrm{mol} . \mathrm{m}^{-2} \cdot \mathrm{s}^{-1}$ e $1.495 \mu \mathrm{mol} . \mathrm{m}^{-2} . \mathrm{s}^{-1}$ na estação seca, e entre $525 \mu \mathrm{mol} \cdot \mathrm{m}^{-2} \cdot \mathrm{s}^{-1}$ a $1.336 \mu \mathrm{mol} \cdot \mathrm{m}^{-2} \cdot \mathrm{s}^{-1}$ na estação chuvosa.

No sub-bosque da floresta, na estação seca, as parcelas que não receberam intervenções silviculturais apresentaram DFF variando de $1,1 \mu \mathrm{mol} . \mathrm{m}^{-2} \cdot \mathrm{s}^{-1} \mathrm{a}$ $659 \mu \mathrm{mol} \cdot \mathrm{m}^{-2} \cdot \mathrm{s}^{-1}$, com média de $160 \mu \mathrm{mol} \cdot \mathrm{m}^{-2} \cdot \mathrm{s}^{-1}$ e $50 \%$ da DFF entre $50 \mu \mathrm{mol} \cdot \mathrm{m}^{-2} \cdot \mathrm{s}^{-1}$ e $206 \mu \mathrm{mol} \cdot \mathrm{m}^{-2} \cdot \mathrm{s}^{-1}$. Na estação chuvosa, a DFF variou entre $1,5 \mu \mathrm{mol} \cdot \mathrm{m}^{-2} \cdot \mathrm{s}^{-1} \mathrm{e} 332 \mu \mathrm{mol} \cdot \mathrm{m}^{-2} \cdot \mathrm{s}^{-1}$, commédiade $23 \mu$ mol. $\mathrm{m}^{-2} \cdot \mathrm{s}^{-1} \mathrm{e} 50 \%$ daDFFentre $5 \mu$ mol. $\mathrm{m}^{-2} \cdot \mathrm{s}^{-1} \mathrm{e}$ $18 \mu \mathrm{mol} \cdot \mathrm{m}^{-2} \cdot \mathrm{s}^{-1}$.

As parcelas que receberam tratamentos silviculturais apresentaram DFF mais altas do que as áreas controle. As parcelas do tratamento 2 (liberação de árvores desejáveis) apresentaram DFF na estação seca variando de $8 \mu \mathrm{mol} . \mathrm{m}^{-2} . \mathrm{s}^{-1}$ a $1.033 \mu \mathrm{mol} . \mathrm{m}^{-2} . \mathrm{s}^{-1}$ (média de $\left.247 \mu \mathrm{mol} . \mathrm{m}^{-2} \cdot \mathrm{s}^{-1}\right)$, com $50 \%$ da DFF entre $97 \mu \mathrm{mol} \cdot \mathrm{m}^{-2} \cdot \mathrm{s}^{-1}$ e $324 \mu \mathrm{mol} \cdot \mathrm{m}^{-2} \cdot \mathrm{s}^{-1}$. Na estação chuvosa, a variação foi de $2 \mu \mathrm{mol} \cdot \mathrm{m}^{-2} \cdot \mathrm{s}^{-1}$ a $653 \mu \mathrm{mol} \cdot \mathrm{m}^{-2} \cdot \mathrm{s}^{-1}$, com média de $55 \mu \mathrm{mol} \cdot \mathrm{m}^{-2} \cdot \mathrm{s}^{-1}$ e com $50 \%$ da DFF entre $12 \mu \mathrm{mol} \cdot \mathrm{m}^{-2} \cdot \mathrm{s}^{-1} \mathrm{e}$ $56 \mu \mathrm{mol} \cdot \mathrm{m}^{-2} \cdot \mathrm{s}^{-1}$.

A DFF nas parcelas sob o tratamento 3 (liberação de desejáveis mais corte de cipós) na estação seca variou de $5 \mu \mathrm{mol} \cdot \mathrm{m}^{-2} \cdot \mathrm{s}^{-1}$ a $922 \mu \mathrm{mol} \cdot \mathrm{m}^{-2} \cdot \mathrm{s}^{-1}$, com média de $211 \mu \mathrm{mol} . \mathrm{m}^{-2} \cdot \mathrm{s}^{-1}$ e $50 \%$ da DFF entre $70 \mu \mathrm{mol} \cdot \mathrm{m}^{-2} \cdot \mathrm{s}^{-1} \mathrm{e}$ $303 \mu \mathrm{mol} \cdot \mathrm{m}^{-2} \cdot \mathrm{s}^{-1}$. Na estação chuvosa a média foi de $56 \mu$ mol. $\mathrm{m}^{-2} \cdot \mathrm{s}^{-1}$, variando de $4 \mu \mathrm{mol} \cdot \mathrm{m}^{-2} \cdot \mathrm{s}^{-1} \mathrm{a} 418 \mu \mathrm{mol} \cdot \mathrm{m}^{-2} \cdot \mathrm{s}^{-1} \mathrm{e}$ com $50 \%$ da DFF entre $12 \mu \mathrm{mol} \cdot \mathrm{m}^{-2} \cdot \mathrm{s}^{-1}$ e $59 \mu \mathrm{mol} \cdot \mathrm{m}^{-2} \cdot \mathrm{s}^{-1}$.

Revista Árvore, Viçosa-MG, v.36, n.6, p.1135-1144, 2012 
Finalizando, o tratamento 4 (liberação de desejáveis mais corte de cipós e plantio de enriquecimento) apresentou na estação seca DFF variando de $12 \mu \mathrm{mol} . \mathrm{m}^{-}$ ${ }^{2} \cdot \mathrm{s}^{-1}$ a $838 \mu \mathrm{mol} \cdot \mathrm{m}^{-2} \cdot \mathrm{s}^{-1}$, com média de $207 \mu \mathrm{mol} \cdot \mathrm{m}^{-2} \cdot \mathrm{s}^{-1}$ e metade da DFF entre $76 \mu \mathrm{mol} . \mathrm{m}^{-2} \cdot \mathrm{s}^{-1}$ e $293 \mu \mathrm{mol} . \mathrm{m}^{-}$ ${ }^{2} \cdot \mathrm{s}^{-1}$. Na estação chuvosa a DFF média foi $56 \mu$ mol.m${ }^{2} . \mathrm{s}^{-1}$, variando de $2 \mu \mathrm{mol} . \mathrm{m}^{-2} . \mathrm{s}^{-1}$ a $351 \mu \mathrm{mol} . \mathrm{m}^{-2} . \mathrm{s}^{-1}$, com $50 \%$ da DFF entre $12 \mu \mathrm{mol} \cdot \mathrm{m}^{-2} \cdot \mathrm{s}^{-1}$ e $68 \mu \mathrm{mol} \cdot \mathrm{m}^{-2} \cdot \mathrm{s}^{-1}$.

Essas variações nas densidades de fluxo de fótons mensuradas, entre os tratamentos silviculturais, nas estações seca e chuvosa, assim como os valores encontrados a pleno sol nas duas estações climáticas, são mais bem visualizadas na Figura 1.

Os percentuais de sombreamento no sub-bosque da floresta foram considerados significativamente diferentes entre as duas estações climáticas (ANOVA, p<0,001).

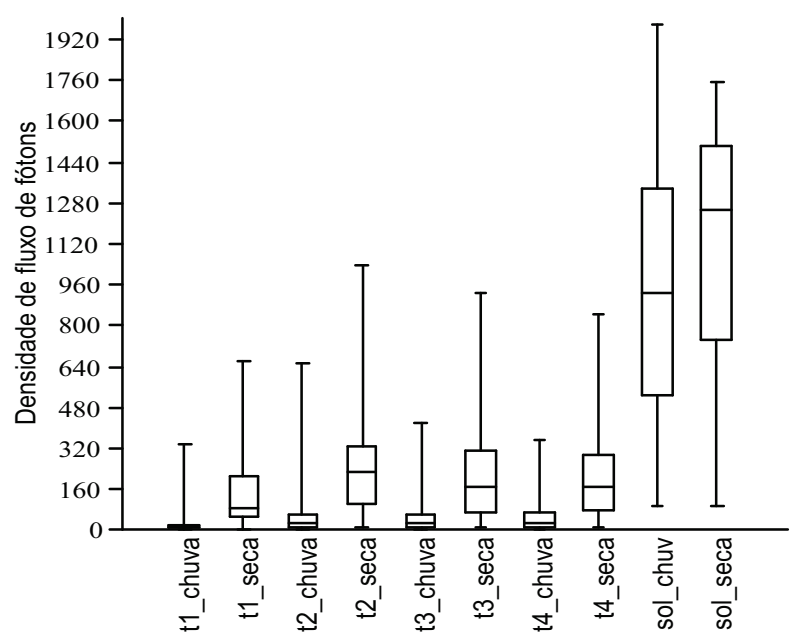

Figura 1 - Densidades de fluxo de fótons (DFF) $\left(\mu \mathrm{mol} . \mathrm{m}^{-2} \cdot \mathrm{s}^{-1}\right)$ na floresta estacional semidecídua, sob manejo, em Pirenópolis, Goiás. São mostradas as áreas controle (t1), os tratamentos silviculturais (t2 a t4) e a condição a pleno sol ( sol), nas duas estações climáticas (seca e chuva). As medições aconteceram na estação chuvosa entre os dias 07 e 10 de junho de 2006 e na estação seca entre 29 de agosto e 01 de setembro de 2007.

Figure1 - Photon flux densities (DFF) $\left(\mu \mathrm{mol} . \mathrm{m}^{-2} \cdot \mathrm{s}^{-1}\right)$ in semideciduous forest management in Pirenópolis, Goiás, Brazil. The ficure shows the control areas $(t 1)$, the silvicultural treatments ( $t 2$ to $t 4)$ and conditions in full sun (sol), in two seasons [dry (seca) and wet (chuva)]. The measurements took place in the rainy season from day 7 and 10 June 2006 and in the dry season from August 29 to September 1, 2007.
As alterações no sub-bosque provocadas pelos tratamentos silviculturais foram suficientes para que as porcentagens de sombreamento em cada tratamento fossem também consideradas estatisticamente diferentes (ANOVA, p<0,001) (Tabela 1). No entanto, não foi verificada diferença estatística nas porcentagens de sombreamento entre as alturas de medida (1,3 m versus ao nível do solo), nem foram verificadas interações entre quaisquer fatores analisados (tratamentos, estações climáticas e alturas de medida), significando que as diferenças nas porcentagens de sombreamento na floresta entre os tratamentos foram independentes das estações climáticas (seca ou chuva) e das alturas de medida (1,3 m e ao nível do solo).

Para identificar os tratamentos silviculturais que foram estatisticamente diferentes entre si, os percentuais médios de sombreamento em cada tratamento foram testados pelo teste de Tukey a 5\% de probabilidade.

Nesse caso, foi verificada diferença estatística entre a área controle e os demais tratamentos $(\mathrm{p}<0,05)$, sendo que os percentuais de sombreamento no controle

Tabela 1 - Análise de Variância para os percentuais de sombreamento no sub-bosque da floresta estacional semidecídua, sob manejo, em Pirenópolis, Goiás. Foi considerado o esquema fatorial em blocos casualizados com três fatores: tratamentos silviculturais, em quatro níveis (t1 a t4); alturas de medida, em dois níveis $(1,3 \mathrm{~m}$ e ao nível do solo); e estações climáticas, em dois níveis (seca e chuva). n.s. = Não significativo.

Table1 - Analysis of variance for the percentage of shading in the understory of the forest seasonal semideciduos management in Pirenópolis, Goias, Brazil. It was considere as a factorial randomized block design with three factors: silvicultural treatments at four levels (T1 to T4); heights measurement at two levels (1.3 meters at ground level), and seasons, on two levels (dry and wet). n.s. $=$ not significant.

\begin{tabular}{lcccc}
\hline F.V. & G.L. & Q.M. & F & P \\
\hline Bloco (B/L)/A & 12 & 0,00495 & & \\
Tratamento (T) & 3 & 0,05012 & 9,43 & 0,001 \\
Estação climática (A) & 1 & 0,928434 & 187,7 & 0,001 \\
Altura de medida (L) & 1 & 0,00948 & 1,91 & n.s. \\
T x A & 3 & 0,002751 & 0,21 & n.s. \\
T x L & 3 & 0,000369 & 0,06 & n.s. \\
A x L & 1 & 0,000267 & 0,05 & n.s. \\
T x A x L & 3 & 0,000116 & 0,02 & n.s. \\
Resíduo & 36 & 0,005313 & & \\
\hline
\end{tabular}

Revista Árvore, Viçosa-MG, v.36, n.6, p.1135-1144, 2012 
foram superiores aos encontrados nos tratamentos variando de $97,5 \%$ na estação chuvosa a $86,9 \%$ na estação seca, enquanto que nos tratamentos os percentuais de sombreamento variaram de $93,7 \%$ a $94 \%$ na estação chuvosa e de $77 \%$ a $80,5 \%$ na estação seca, sem diferença estatística significativa entre eles ( $\mathrm{t} 2$ versus $\mathrm{t} 3$; $\mathrm{t} 2$ versus $\mathrm{t} 4$; $\mathrm{t} 3$ versus $\mathrm{t} 4)$.

\section{DISCUSSÃO}

Os mais altos valores de DFF encontrados na estação seca refletiram a maior abertura do dossel nessa estação em relação à estação chuvosa, o que é comum em florestas estacionais em razão da queda de folhas das árvores no período de estiagem, como era esperado.

Os percentuais de sombreamento encontrados na Floresta Estacional Semidecidual, que variaram de $86,9 \%$ na estação seca a $97,5 \%$ na estação chuvosa, na área-controle, foram superiores aos encontrados em Florestas Deciduais no Vale do Rio Paranã, em Goiás, por Nascimento (2005). Esse autor constatou percentuais de sombreamento que variaram entre $25 \%$ e $32 \%$ na estação seca e entre $90,4 \%$ e $94,3 \%$ na estação chuvosa. Os valores encontrados nessas duas formações florestais corroboraram a maior abertura do dossel, associada à estação seca em relação à estação chuvosa em Florestas Estacionais e confirmaram a diferença entre essas duas tipologias florestais quanto à abertura do dossel, em razão da maior taxa de deciduidade das árvores e do maior espaçamento entre as árvores nas Florestas Decíduas em relação às Semidecíduas, como discutido por Ribeiro e Walter (1998) e Felfili (2001).

Em Florestas de Galeria no Brasil Central, no entanto, Felfili e Abreu (1999) encontraram percentuais de sombreamento variando de $93,5 \%$ a $99,7 \%$ no sub-bosque, independentemente da estação climática. Essa pequena variação nos percentuais de sombreamento em Matas de Galeria em relação às florestas estacionais, encontradas por Felfili e Abreu (1999), versus a maior variação na Floresta Semidecídua estudada, pode refletir a maior disponibilidade hídrica nas florestas ripárias ao longo do ano, o que permite alta cobertura do dossel, mesmo na estação seca. Isso pode ajudar a explicar a deciduidade das árvores nas florestas estacionais em função do estresse hídrico dos solos.

Não só gradientes climáticos e edáficos e a natureza da formação florestal influenciam a quantidade de luz que atravessa o dossel. A porcentagem de sombreamento no sub-bosque também varia com a presença de clareiras. Em geral, quanto mais densa a tipologia florestal, maior a diferença no sombreamento entre clareiras e áreas não perturbadas. Esse padrão foi observado por Muniz (2004) e se repetiu neste estudo, pois se verificou diferença significativa nos percentuais de sombreamento entre a área-controle (86,9\% de sombreamento na seca a 97,5\% de sombreamento na chuva) e as áreas sob intervenções silviculturais (77\% a 80,5\% de sombreamento na seca a 93,7 a $94 \%$ de sombreamento na chuva).

Adicionalmente, a densidade de fluxo de fótons também varia em relação ao tamanho da clareira dentro de cada tipologia florestal. Estudos têm apontado menor amplitude de variação em áreas mais abertas, com menor densidade de árvores, como em Cerradão (28\%), contra outras formações florestais mais densas, como em floresta de restinga, onde a variação foi de $87 \%$; floresta ombrófila densa, com variação de $88 \%$; e Floresta Estacional Semidecidual, que apresentou variação de $91 \%$ entre clareiras grandes e pequenas (MUNIZ, 2004).

Os níveis de DFF medidos na Floresta Semidecidual estudada permitiram verificar a eficiência dos tratamentos silviculturais na abertura do dossel. Consequentemente, os mais altos percentuais de sombreamento estiveram associados à área-controle (Figura 1). No entanto, o corte de cipós de grande porte na floresta não levou a um aumento significativo na incidência de luz no sub-bosque, pois não foram verificadas diferenças estatísticas nas porcentagens de sombreamento entre o tratamento silvicultural sem corte de cipós, tratamento 2, onde ocorreu apenas a liberação de árvores desejáveis, e os tratamentos com corte de cipós, tratamento 3 (liberação de árvores desejáveis mais corte de cipós) e tratamento 4 (liberação de árvores desejáveis mais corte de cipós e plantio de enriquecimento).

A diferença estatisticamente significativa (ANOVA) na DFF entre as estações climáticas era esperada devido à natureza da floresta em estudo. Complementarmente, os valores semelhantes de sombreamento entre as alturas de medida (1,30 m e ao nível do solo) confirmaram o impacto reduzido das intervenções silviculturais aplicadas no experimento. Tais intervenções visaram intervir na estrutura arbórea da floresta e não modificar o ambiente no sub-bosque para não interferir negativamente na dinâmica da regeneração natural, como analisado e discutido por Venturoli et al. (2011a).

Revista Árvore, Viçosa-MG, v.36, n.6, p.1135-1144, 2012 
A falta de interação estatística (ANOVA) entre os percentuais de sombreamento na floresta, em função dos tratamentos silviculturais, das estações climáticas e das diferentes alturas de medida confirmaram a aditividade e a independência dos tratamentos silviculturais.

Com os valores de sombreamento encontrados na área-controle, pode-se caracterizar a taxa de deciduidade da floresta estudada, enquadrando-a na definição de Floresta Estacional Semidecidual, dada por Veloso et al. (1991), Ribeiro e Walter (1998) e Felfili (2001). Esses autores consideraram como semidecíduas as florestas com cobertura foliar arbórea entre 70 e $95 \%$ na estação chuvosa e superior a $50 \%$ na estação seca.

\section{CONCLUSÃO}

Embora as intervenções silviculturais tenham sido suficientes para modificar o ambiente de luz no subbosque da floresta, verificou-se grande variação na DFF entre as duas estações climáticas, tanto a pleno sol quanto no interior da floresta. Em média, $77 \%$ da DFF ficou retida no dossel na estação seca e 97,5\% na estação chuvosa.

As porcentagens de sombreamento, em razão dos tratamentos silviculturais, foram independentes das alturas de medida (1,30 e ao nível do solo), e a diferença nos percentuais de sombreamento entre os tratamentos foi considerada constante entre as duas estações climáticas.

Essas informações serão importantes em análises populacionais e de comunidade que investigam o crescimento das espécies arbóreas e da regeneração natural e em estudos de cobertura do solo por espécies invasoras, em relação à abertura do dossel provocada por tratamentos silviculturais. Além disso, podem auxiliar na validação desse sistema de manejo florestal proposto para as Florestas Estacionais Semideciduais no Brasil Central, conservando os remanescentes florestais da região e gerando emprego e renda para a população rural.

\section{AGRADECIMENTOS}

José Carlos Souza-Silva pelo empréstimo de um sensor de luz, ao Dr. Francisco Ozanan, NOVACAP, Brasília, DF, e à Profa.JeanineFelfili (in memoriam), pelas orientações.

\section{REFERÊNCIAS}

AUGSPURGER, C. K. Light requirements of neotropical tree seedling: a comparative study of growth and survival. Journal of Ecology, v.72, n.3,p.777-795, 1984.

BRADY, N. C.; WEIL, R. R. The nature and properties of soils. New York: Prentice Hall, 2001.960p.

CARVALHO, J. O. P.; SILVA, J. N. M.; LOPES, J. C. A. Growth rate of a terra firme rain forest in Brazilian Amazonia over an eight-year period in response to logging. ActaAmazonica, v.349, n.2, p.209-217, 2004.

COLlet, C.; CHENOST, C. Using competition and light estimates to predict diameter and height growth of naturally regenerated beech seedlings growing under changing canopy conditions.Forestry, v.79, n.5, p.489-502, 2006.

D’ANTONIO, C. M.; VITOUSEK, P. M.

Biological invasions by exotic grasses, the grass/fire cycle, and global change. Annual Review of Ecology and Systematics, v.23, p.63-87, 1992.

DENSLOW, J. S. et al.Growth responses of tropical shrubs to tree fall gap environments.Ecology, v.71, n.1, p.165-179, 1990.

ENGELBRECHT, B. M. J.; HERTZ, H. M. Evaluation of different methods to estimate understorey light conditions in tropical forest. Journal of Tropical Ecology, v.17, n.2, p.207-224, 2001.

FELFILI, J. M. Principais fisionomias do espigão mestre do São Francisco. In: FELFILI, J. M.; SILVA JÚNIOR, M. C. (Org.).Biogeografia do bioma cerrado: estudo fitofisionômico da Chapada do Espigão Mestre do São Francisco. Brasília: Universidade de Brasília, 2001. p.18-30.

FELFILI, J. M.; ABREU, H. M. Regeneração natural de RoupalamontanaAubl., Piptocarphamacropoda Back. ePersea fuscaMez. em quatro condições ambientais na mata de galeria do Gama - DF. Cerne, v.5, n.2, p.125-132, 1999. 
FELFILI, J. M. et al.Semideciduous secondary forest management in Vagafogo, Goiás, Brazil. In: ANNUAL MEETING OF THE ASSOCIATION FOR TROPICAL BIOLOGY AND CONSERVATION,2005, Uberlândia.Anais...Uberlândia:

UniversidadeFederal de Uberlândia, 2005. p.165.

FREITAS, J. V. Improving tree selection for felling and retention in natural forest in Amazônia through spatial control and targeted seed tree retention: a case study of a forest management project in Amazonas state, Brazil. 2004, 190f. Thesis (Doctor of Philosophy)- University of Aberdeen, Aberdeen,2004.

GERHARDT, K. Effects of root competition and canopy openness on survival and growth of tree seedlings in seasonal dry Forest.

Forest Ecologyand Management, v.82, n.1, p.33-48, 1996.

\section{INSTITUTO BRASILEIRO DE GEOGRAFIA E} ESTATÍSTICA -IBGE. Mapa de solos do Brasil. Rio de Janeiro: 2001.Escala 1:5.000.000.

\section{INSTITUTO BRASILEIRO DE GEOGRAFIA E} ESTATÍSTICA - IBGE. Mapa de vegetação do Brasil.Rio de Janeiro: 2004.Escala 1:5.000.000

INSTITUTO NACIONAL DE METEOROLOGIAINMET. Normais climatológicas. 2006.Disponível em:<www.inmet.gov.br>.Acessoem: 15 jan.2006.

JENNINGS, S. B.; BROWN, N. D.; SHEIL, D. Assessing forest canopies and understorey illumination: canopy closure, canopy cover and other measures. Forestry, v.72, n.1, p.59-73, 1999.

KEELING, H. C.; PHILLIPS, O. L. A calibration method for the crown illumination index for assessing forest light environments.Forest Ecology and Management, v.242, n.2/3, p.431-437, 2007.

KENT, M. Vegetation description and data analysis: a practical approach. 2.ed. London: Wiley-BlackWell, 2012. 428p.
KENT, M.; COKER, P. Vegetation description and analysis: a practical approach.London: Belhaven Press, 1992. 363p.

MARIMON, B. S. Dinâmica de uma floresta monodominante de Brosimumrubescens Taub. e comparação com uma floresta mista em Nova Xavantina-MT. 2005. 263f. Tese (Doutorado em Ecologia) -Universidade de Brasília, Brasília, 2005.

MUNIZ, M. R. A. Estudo do regime de luz nas quatro principais formações fitogeográficas no estado de São Paulo durante o inverno do ano de 2003. 2004. 189f. Dissertação (Mestrado em Biologia Vegetal) -Universidade de Campinas,Campinas, 2004.

NASCIMENTO, A. R. T. Variações espaciais e sazonais de radiação solar em fragmentos de floresta estacional decidual em afloramento calcário e sua relação com a distribuição de espécies arbóreas.2005. 143f. Tese (Doutorado em Ecologia) Universidade de Brasília,Brasília, 2005.

NIMER, E. Climatologia do Brasil. Rio de Janeiro: IBGE, 1989. 422p.

PAQUETTE, A.; BOUCHARD, A.; COGLIASTRO, A. Morphological plasticity in seedlings of three deciduous species under shelterwood under-planting management does not correspond to shade tolerance ranks. Forest Ecology and Management, v.241, n.1/3, p.278-287, 2007.

PARIONA, W.; FREDERICKSEN, T. S.; LICONA, J. C. Natural regeneration and liberation of timber species in logging gaps in two Bolivian tropical forests. Forest Ecology and

Management, v.181, n.3, p.313-322, 2003.

PEREIRA, B. A.; VENTUROLI, F.; CARVALHO, F. A. Florestas estacionais no cerrado: uma visão geral. Pesquisa Agropecuária Tropical, v.41, n.3, p.446-455, 2011.

RIBEIRO, J. F.; WALTER, B. M. T. Fitofisionomias do bioma cerrado. In: SANO, S. M.; ALMEIDA,S. P. (Ed.). Cerrado ambiente e

flora.Planaltina: Embrapa, 1998.p.89-166.

Revista Árvore, Viçosa-MG, v.36, n.6, p.1135-1144, 2012 
ROSSATTO, D. R. et al.Características funcionais de folhas de sol e sombra de espécies arbóreas em uma mata de galeria no Distrito Federal, Brasil. Acta Botânica Brasilica,v.24, n.3, p.640-647, 2010.

SILVA, J. N. M.et al.Growth and yield of a tropical rainforest in the Brazilian Amazon 13 years after logging. Forest Ecology and

Management, v.71, n.3, p.267-274, 1995.

SMITH, D. M. The practice of silviculture. New York: Wiley \& Sons, 1986. 527p.

SOCOLOWSKI, F.;TAKAKI, M. Germinação de sementes e emergência de plântulas de Tabebuia rosea (Bertoloni) a.p. de Candolle

(Bignoniaceae), uma espécie exótica com potencial invasor.RevistaÁrvore, v.31, n.2, p.229-238, 2007.

SOUZA, R. P.; VÁLIO, I. F. M. Seed size, seed germination, and seedling survival of Brazilian tropical tree species differing in sucessional status. Biotropica, v.33, n.3, p.447-457, 2001.

SOUZA-SILVA, J. C.et al.Desenvolvimento inicial de Cabralea canjerana Saldanha sob diferentes condições de luz.Boletim do

HerbárioEzechias Paulo Heringer, v.4, p.80-86, 1999.

SWAINE, M. D.; WHITMORE, T. C. On the definition of ecological species groups in tropical rain forests.Vegetatio, v.75, n.2, p.81-86, 1988.

VELOSO, H. P.; RANGEL FILHO, A. L.; LIMA, J. C. A. Classificação da vegetação brasileira adaptada a um sistema universal. Rio de Janeiro: IBGE, 1991. 123p.

VENTUROLI, F. Manejo de floresta estacional semidecídua secundária, em Pirenópolis, Goiás. 2008. 188f. Tese (Doutorado em Ciências Florestais) - Universidade de Brasília, Brasília, 2008.
VENTUROLI, F.; FAGG, C. W.; FAGG, J. M. F. Crescimento de uma floresta estacional semidecídua secundária sob manejo em relação a fatores ambientais, em Pirenópolis, Goiás.

Revistade Biologia Neotropical, v.7, n.2, p.1-11,2010c.

VENTUROLI, F.; FAGG, C. W.; FELFILI, J. M. Desenvolvimento inicial de DipteryxalataVogel e MyracrodruonurundeuvaAllemão em plantio de enriquecimento de uma floresta estacional semidecídua secundária.BioscienceJournal, v.27, n.3, p.482-493, 2011 b.

VENTUROLI, F.; FELFILI, J. M.; FAGG, C. W. Avaliação temporal da regeneração natural em uma floresta estacional semidecídua secundária, em Pirenópolis, Goiás.Revista Árvore, v.35, n.3, p.473-483, 2011 a.

VIEIRA, D. L. M.; SCARIOT, A. Principles of natural regeneration of tropical dry forests for restoration. Restoration Ecology, v. 14, n.1, p.11-20, 2006.

WADSWORTH, F. H.; ZWEEDE, J. C. Liberation: Acceptable production of tropical forest timber. Forest Ecology and Management, v.233, n.1, p.45-51, 2006.

WANG, Q. et al.Variation on PAR to global solar radiation ratio along altitude gradient in Naeba Mountain. Theoretical and Applied Climatology, v.87, p.239-253, 2007.

WHITMORE, T. C. Canopy gaps and the two major groups of forest tree. Ecology, v.70, n.3, p.536-538, 1989 .

ZAR, J. H. Biostatistical analysis. New Jersey: Prentice-Hall, 2010.944p.

ZIPPERLEN, S.; PRESS, M. Photosynthesis in relation to growth and seedling ecology of two dipterocarp rain forest tree species. Journal of Ecology, v.84, n.6, p.863-876, 1996. 